Yüzüncü Y1 Üniversitesi
Tarim Bilimleri Dergisi

Araştırma Makalesi (Research Article)

Roka (Eruca sativa L.) Yetiștiriciliğinde Katı ve Sıvı Organik Gübre Uygulamalarının Spektral Yansıma Üzerine Etkisi

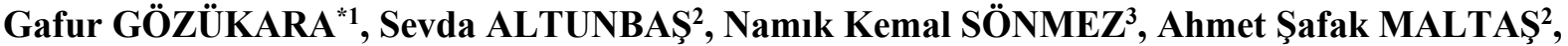 Mustafa KAPLAN ${ }^{2}$
}

${ }^{1}$ Eskişehir Osmangazi Üniversitesi, Ziraat Fak., Toprak Bilimi ve Bitki Besleme B., 26160, Eskişehir, Türkiye

${ }^{2}$ Akdeniz Üniversitesi, Ziraat Fakültesi, Toprak Bilimi ve Bitki Besleme Bölümü, 07059, Antalya, Türkiye

${ }^{3}$ Akdeniz Üniversitesi, Fen Fakültesi, Uzay Bilimleri ve Teknolojileri Bölümü, 07059, Antalya, Türkiye

*Sorumlu yazar e-posta: ggozukara@ogu.edu.tr

\section{Makale Bilgileri}

Geliş: 23.07.2019

Kabul: 03.11.2019

Online Yayınlanma 31.12.2019

DOI: $10.29133 /$ yyutbd.595836

\section{Anahtar kelimeler}

Roka,

Kat1-s1v1 organik gübre,

Spektral yansıma
Öz: Bitkilerin spektral yansıma karakteristikleri bitki besin maddesi konsantrasyonları, stres ve diğer faktörlerin etkisi ile vejetasyon periyodu boyunca farkl11lk göstermektedir. Roka (Eruca sativa L.) gibi yaprağ 1 yenen sebzelerde verimi arttrmak ve tüketicinin tercih ettiği koyu yeşil yaprak rengini kısa sürede sağlayabilmek için yoğun gübreleme yapılmaktadır. Bu çalışmada roka bitkisine artan dozlarda tabandan uygulanan katı ve sivı organik gübre uygulamalarının, elektromanyetik spektrumun farklı dalga boyu aralı̆ıındaki enerji kullanımı üzerine etkileri araştııılmıştır. Çalışma kontrollü sera ortamında tesadüf parselleri deneme desenine göre yürütülmüştür. Denemede bitki yetişme periyodu süresince farklı dozlarda tabandan katı organik gübre (KOG) ve damlamadan sıvı organik gübre (SOG) uygulanmıştır. Bu süreçte elektromanyetik spektrumun 330-1075 nm dalga boyu aralı̆ında el spektroradyometresi ile spektroradyometrik ölçümler gerçekleştirilmiştir. Araştırma sonucunda, her ölçümde uygulamalar ve dönemler arasında istatistiksel olarak farklılıkların olduğu tespit edilmiştir. Katı+sıvı organik gübre uygulamalarının spektral yansıma üzerinde oluşturduğu varyasyonun en fazla ve en az olduğu ölçümler sırasıyla mavi band bölgesinde; 4. ve 8. ölçümler, yeşil band bölgesinde; 5 . ve 3. ölçümler, kırmızı band bölgesinde; 2. ve 8 . ölçümler, yakın infrared band bölgesinde ise; 2 . ve 7 . ölçüm dönemlerinde tespit edilmiștir. Bu sonuçlar doğrultusunda varyasyonun en fazla ve en az olduğu ölçüm dönemlerinin bitki stres koşullarının tespit edilmesinde belirleyici olduğu sonucuna ulaşılmıştır.

\section{The Effect of Solid and Liquid Organic Fertilizer Applications on Spectral Reflection in Rocket (Eruca sativa L.) Cultivation}

\section{Article Info}

Received: 23.07.2019

Accepted: 03.11.2019

Online Published 31.12.2019

DOI: $10.29133 /$ yyutbd.595836

Keywords

Rocket,

Solid-liquid organic fertilizer, Spectral reflection

\begin{abstract}
Spectral reflection characteristics of plants vary during the vegetation period with the effect of plant nutrient concentrations, stress and other factors. Intense fertilization is done in order to increase the yield and to provide the dark green leaf color preferred by the consumer in a short time, such as rocket (Eruca sativa L.). In this study, the effects of solid and liquid organic fertilizer applications applied to the arugula at increasing doses on the energy usage in different wavelength ranges of the electromagnetic spectrum were investigated. The study was carried out in a controlled greenhouse environment according to randomized plot design. In the experiment, solid organic fertilizer (KOG) and liquid organic fertilizer (SOG) were applied at different doses throughout the plant growing period. In this process, spectroradiometric measurements were
\end{abstract}


performed by hand spectroradiometer in the wavelength range of 330-1075 $\mathrm{nm}$ of the electromagnetic spectrum. As a result of the research, it has been found that there are statistical differences between applications and periods in each measurement. Measurements where the variation on spectral reflection of the solid + liquid organic fertilizer applications were the highest and the least were in the blue band region respectively; Measurements 4 and 8, in the green band region; Measurements 5 and 3, in the red band region; Measurements 2 and 8 are in the near infrared band; It was determined during the 2nd and 7 th measurement periods. In line with these results, it was concluded that the measurement periods with the highest and lowest variations were determinative in determining plant stress conditions.

\section{Giriş}

Anavatanı Akdeniz bölgesi olarak kabul edilen roka (Eruca sativa L.) yaprakları tüketilen bir sebzedir (Vural ve ark., 2000). Roka bitkisinin Türkiye ölçeğinde 10.38 bin dekar üretim alanıyla birlikte 12.93 ton üretim miktarı bulunmaktadır. Roka yetiştiriciliğinde toplam üretim alanının $\% 2.55$, üretim miktarının ise \%1.69'u Antalya ilinde yapılmaktadır (Anonim, 2018). Roka (Eruca sativa L.) gibi yaprağı yenen sebzelerde verimi arttırmak ve tüketicinin tercih ettiği koyu yeşil yaprak rengini kısa zamanda sağlayabilmek için yoğun gübreleme yapılmaktadır. Halbuki üretim alanlarında toprak verimliliğini korumak, verim, kalite ve karlılık dengesini koruyabilmek için kullanılacak gübrelerin kaynağının, kullanım dozunun ve zamanının iyi belirlenmesi gerekir (Gözükara ve ark., 2014; Gözükara ve ark., 2016; Kalkan ve ark., 2017). Göz önünde bulundurulması gereken bu faktörler üretim periyodu 1-1.5 ay olan roka bitkisinin yetiştiriciliğinde ise büyük önem taşımaktadır.

Binlerce yıldır Anadolu topraklarında tarım yapılması nedeniyle topraklar verimsizleşmiş, erozyon nedeniyle taşınmış, iklim değişimi nedeniyle topraklar ya tuzlanmış ya da aşırı yağışlarla kütle hareketlerine maruz kalıp degrade olmuştur. Tüm bu sebepler topraklarımızın organik madde miktarını azaltmış buna bağlı olarak, özellikle organik gübre kullanımı zorunlu olmuştur. Organik gübreleme; toprağın fiziksel, kimyasal (Alagöz ve ark., 2006; Yılmaz ve Sönmez, 2017) ve biyolojik (Uz ve ark., 2016) özelliklerinin iyileştirmekle çevre üzerine olumlu etkiler sağlamaktadır. Böylelikle ekolojik ve ekonomik anlamda hem bölgesel hem de küresel katkı sağlamaktadır. Bu olumlu etkiler dikkate alındığında, toplam gübreleme oranı içerisinde katı ve sıvı organik gübre kullanımı, gün geçtikçe artış eğilimindedir (Kalkan ve ark., 2017). Gübrenin az veya çok uygulanması bitkiler için stres koşulları oluşturmaktadır. Stres koşullarının belirlenmesinde kullanılan yeni teknolojik yöntemlerden birisi de uzaktan algılama teknolojisidir (Jackson 1984). Uzaktan algılama çalışmalarında temel unsur, bitkilerin elektromanyetik spektruma verdikleri tepkinin belirlenmesidir. Bitkiler, spektrumun farklı dalga boyu bölgelerinde farklı absorbsiyon ve yansitma özellikleri gösterirler (Merzlyak ve ark., 2003; Sonmez ve ark., 2015; Gözükara ve ark., 2019). Spektroradyometre ile kaydedilen spektral yansıma sayesinde bitkilerin mineral besin elementi konsantrasyonu, gelişme durumları ve stres koşullarının izlenmesi ve arasındaki ilişkinin ortaya çıkarılması mümkün olabilmektedir (Chappelle ve ark., 1992, Blackmer ve ark., 1994, Zhao ve ark., 2003, 2005; Sari ve ark., 2005a; Zhao ve ark., 2007; Sonmez ve ark., 2008a-b; Altunbas ve ark., 2018a, Altunbaş ve ark., 2018b; Gözükara ve ark., 2019). Uzaktan algılama teknik ve teknolojileri arasında tarla-bahçe-sera ortamlarında, bitkiye yakın tutularak ölçüm yapabilen spektroradyometre gibi cihazlar kullanılmaktadır. Yersel uzaktan algılama ölçümleri olarak da adlandırılan bu spektroradyometrik ölçümlerle, bitki stres koşullarının belirlenmesi ve izlenmesi ile ilgili çalışmalar uzun yıllardan beri yapılmaktadır (Rahman ve ark., 1994; White, 1998; Zhao ve ark., 2005; Viscarra Rossel ve ark., 2006; Sönmez ve ark., 2008; Başayiğit ve ark., 2015; Sönmez ve ark., 2015; Zhao ve ark., 2017; Altunbaş ve ark., 2018a, Altunbaş ve ark., 2018b; Gözükara ve ark., 2019).

Araştırmacılarının stres koşullarının belirlenmesi ve izlenmesi ile ilgili bulguları ve tespitlerinden de anlaşılacağı üzere, bitkilerin spektral yansımalarının dönemlik veya üretim sezonu boyunca değişimlerine ilgi duyarak ayrıntılı çalışma yapma ihtiyacını hissetmişlerdir. Söz konusu bu araştırma ihtiyacının, spektral yansının hangi koşullarda artış ya da azalış eğiliminde olduğunun tam olarak kesinleştirilememiş olmasından kaynaklandığı açıktır. Bu araştırmanın amacı, roka (Eruca sativa L.) 
bitkisine farklı dozlarda uygulanan organik gübrelerin (SOG+KOG) elektromanyetik spektrumun farklı dalga boylarındaki yansıma karakteristiği üzerine etkilerini araştırmaktır.

\section{Materyal ve Yöntem}

\subsection{Materyal}

Türkiye'nin Akdeniz Bölgesinde yer alan Antalya ilinde örtü altı roka yetiştiriciliğinde tercih edilen ve Küçük Çiftlik Tohumculuk tarafindan üretilen Bengi $\mathrm{F}_{1}$ Roka (Eruca sativa L.) çeşiti materyal olarak kullanılmıştır. Çalışma kapsamında her bir parsele (21 farklı parsel) 32 adet roka tohumu ekilmiştir. Deneme 36 53 '54.60 " Kuzey enlemleri ile 30 38' $16.99^{\circ}$ " Doğu boylamları arasında ve $32 \mathrm{~m}$ deniz seviyesinden yükseklikte yer alan kontrollü sera ortamında yürütülmüşsür (Şekil 1).

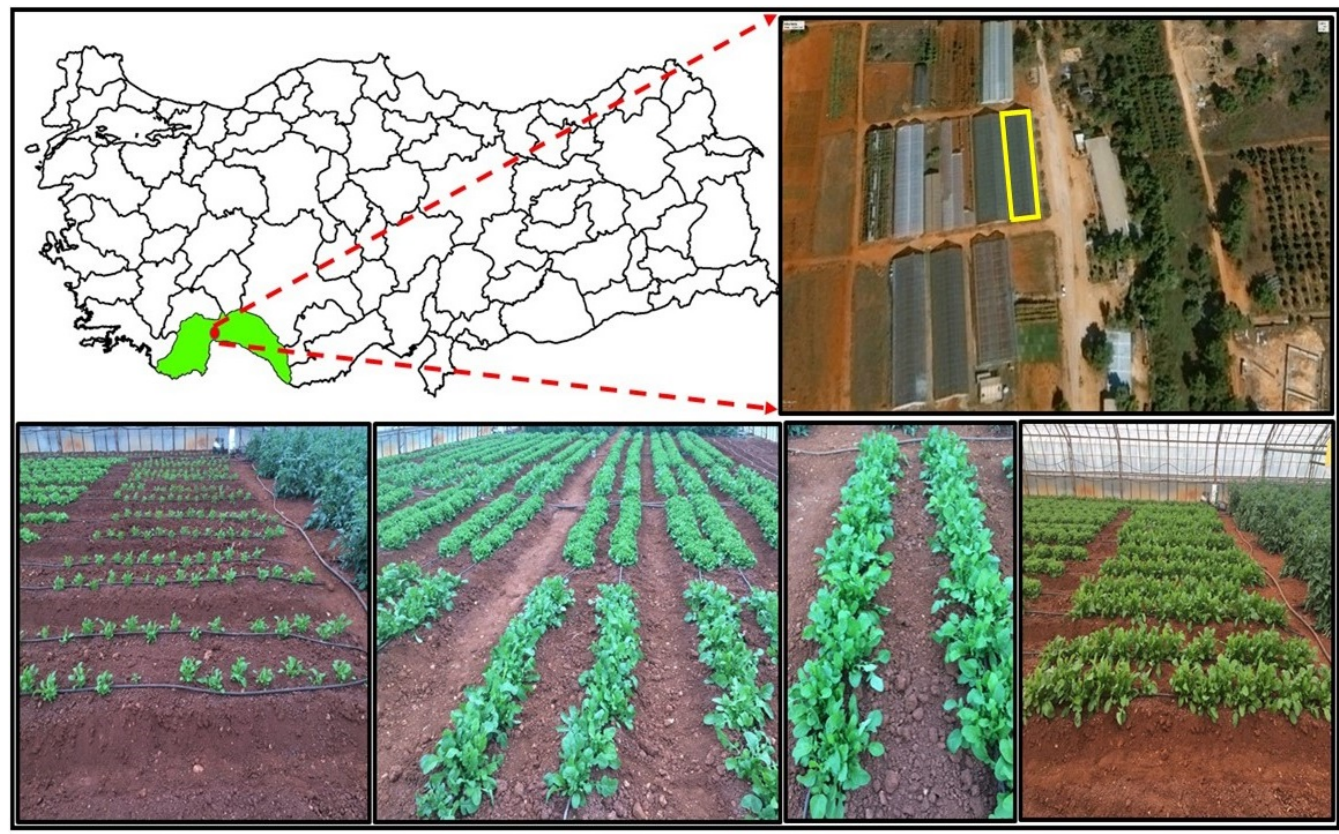

Şekil 1. Çalışma alanının coğrafik konumu ve roka bitkisinin gelişiminden genel görünüm

\subsection{Yöntem}

Araştırma, kontrollü sera koşullarında tesadüf parselleri deneme desenine göre 3 tekerrürlü olarak yürütülmüştür. Çalışma aşamaları; organik gübre uygulamaları, spektral ölçümler ve laboratuvar analizlerinden oluşmaktadır.

\subsubsection{Katı-sıvı organik gübre uygulamaları}

Denemede kontrol uygulaması da dahil tabandan katı ve damlamadan sıvı organik gübre uygulamaları ile birlikte yedi (7) farklı uygulama yapılmıştır (Çizelge 1).

Çizelge 1. Katı sıvı organik gübre uygulamaları

\begin{tabular}{cccccccc}
\hline & $\mathrm{K}_{0}$ & $\mathrm{U}_{1}$ & $\mathrm{U}_{2}$ & $\mathrm{U}_{3}$ & $\mathrm{U}_{4}$ & $\mathrm{U}_{5}$ & $\mathrm{U}_{6}$ \\
\hline Kat1 Organik Gübre $\left(\mathrm{kg} \cdot \mathrm{da}^{-1}\right)$ & 0 & 0 & 300 & 600 & 0 & 300 & 600 \\
Siv1 Organik Gübre $\left(\mathrm{lt.da}^{-1}\right)$ & 0 & 20 & 40 & 20 & 40 & 20 & 40 \\
\hline
\end{tabular}

Katı organik gübreler dikimden önce uygulama dozu kadar parsellere homojen olarak tek seferde uygulanmıştır. Sıvı organik gübreler ise üretim periyodu boyunca parsellere 10 farklı seferde damlamadan uygulanmıştır. Çizelge 2'de denemede uygulanan katı ve sıvı organik gübrelerin bazı özellikleri verilmiştir. 
Çizelge 2. Katı ve sıvı organik gübrelerin bazı kimyasal özellikleri

\begin{tabular}{ccc}
\hline Parametreler & $\begin{array}{c}\text { Katı Organik Gübre } \\
\text { (Altavita) }\end{array}$ & $\begin{array}{c}\text { Siv1 Organik Gübre } \\
\text { (Altaverde) }\end{array}$ \\
\hline Organik madde (\%) & 50 & 20 \\
Hümik+Fülvik asit (\%) & 40 & 15 \\
Toplam N (\%) & 2 & 3 \\
Toplam P (\%) & 2 & 0.7 \\
Toplam K (\%) & 1 & 5 \\
Kuru madde max (\%) & 80 & 40 \\
pH & $5.5-7.5$ & $6-7$ \\
C/N & $15 / 1$ & $4 / 1$ \\
\hline
\end{tabular}

\subsubsection{Spektral ölçümler}

Spektroradyometrik ölçümlerde taşınabilir Analytical Spectral Devices (ASD) FieldSpec FR) Hand Held spektroradyometresi kullanılmıştır. Yapraktan ölçümler Spektrumun 325-1075 nm dalga boyları aralığında bitki probu (plant probe) ve temas probu (kontact probe) ile yapılmıştır. Spektoradyometrik ölçümlerin tamamı bitki gelişimi periyodunda olgunluk dönemine kadar belirli aralıklarla elektromanyetik spektrumun 330-1075 nm dalga boyu aralığında gerçekleştirilmiştir. Çalışmada bitkiyi en iyi temsil eden yapraklar ölçüm amacı ile kullanılmıştır. Sonrasında ise her bir ölçümde elde edilen spektral verilerde veri karmaşasına neden olunmaması amacı ile elde edilen spektral yansıma değerleri mavi $(450-500 \mathrm{~nm})$, yeşil $(501-570 \mathrm{~nm})$, kırmızı $(610-700 \mathrm{~nm})$ ve yakın kızılötesi (NIR) (701-1075 nm) dalga boyu aralıklarında ayrı ayrı kategorize edilerek incelenmiştir.

\subsubsection{Toprak analizleri}

Bitki dikimi öncesinde, toprak örneklerinin EC-pH'ları 1:2.5 toprak:su karışımında (Jackson, 1967), $\mathrm{CaCO}_{3}$ içerikleri Scheibler Kalsimetresiyle (Evliya, 1964), toprak bünyesi hidrometre yöntemine göre (Bouyoucos, 1955), organik madde modifiye Walkley-Black metoduna göre (Black, 1965) belirlenmiştir. Toplam N modifiye Kjeldahl metoduna göre (Kacar 1995), alınabilir P Olsen metoduna göre (Olsen ve Sommers, 1982), değişebilir $\mathrm{K}, \mathrm{Ca}$ ve $\mathrm{Mg}$ analizleri $1 \mathrm{~N}$ amonyum asetat $(\mathrm{pH}=7)$ metoduna göre (Kacar ve İnal, 2008) ve alınabilir Fe, $\mathrm{Zn}, \mathrm{Mn}$ ve $\mathrm{Cu}$ analizleri ise DTPA metoduna göre (Lindsay ve Norwell, 1978) yapılmıştır.

\subsubsection{Istatistik Analizler}

İstatistik analizler için Minitab 17.0 (MINITAB Inc, 2014) ve SPSS 22.0 programları kullanılmıştır (IBM SPSS statistics, 2014).

\section{Bulgular ve Tartışma}

Çalışma alanının toprak analiz sonuçları (Çizelge 3); pH değeri göre hafif alkalin Kellog (1952), $\mathrm{CaCO}_{3}$ içeriği göre yüksek kireçli Evliya (1964), EC tuzsuz (Soil Survey Staff, 1951), organik madde az Horoz (2002), toplam N içeriği iyi Loue (1968), alınabilir P içeriği çok yüksek (Olsen ve Sommers, 1982), değişebilir K içeriği yüksek (Pizer,1967), değiş̧ebilir Ca ve Mg içerikleri iyi (Loue, 1968), alınabilir $\mathrm{Fe}$ ve $\mathrm{Zn}$ içeriklerinin fazla, alınabilir $\mathrm{Mn}$ ile $\mathrm{Cu}$ içeriklerini yeterli olarak değerlendirilmektedir (Lindsay ve Norvell 1978).

Araştırma sonucunda, farklı dozlarda uygulanan katı ve sıvı organik gübrenin mavi, yeşil, kırmızı ve NIR dalga boylarındaki yansıma üzerindeki etkileri varyans analizi ile tespit edilmiştir ( Çizelge 4). Varyans analiz sonuçlarına göre; spektral yansıma üzerine organik gübre dozu, dönem ve doz*dönem interaksiyonun etkileri istatistiksel olarak $\mathrm{P} \leq 0.01$ düzeyinde önemli bulunmuştur (Çizelge 4). 
Çizelge 3. Çalışma alanı topraklarının bazı fiziksel ve kimyasal özellikleri

\begin{tabular}{lc}
\hline Özellikler & Değer \\
\hline Kum $(\%)$ & 40 \\
Silt $(\%)$ & 22 \\
Kil $(\%)$ & 38 \\
EC $(1: 2.5)\left(\mathrm{dS} \mathrm{m}^{-1}\right)$ & 0.69 \\
pH $(1: 2.5)$ & 7.54 \\
Kireç $(\%)$ & 17.40 \\
Organik Madde (\%) & 2.05 \\
N (\%) & 0.12 \\
P (ppm) & 170 \\
K (meq $\left.100 \mathrm{~g}^{-1}\right)$ & 1.46 \\
$\mathrm{Ca}\left(\mathrm{meq} 100 \mathrm{~g}^{-1}\right)$ & 21.30 \\
$\mathrm{Mg}\left(\mathrm{meq}^{\left.-100 \mathrm{~g}^{-1}\right)}\right.$ & 3.88 \\
$\mathrm{Fe}\left(\mathrm{mg} \mathrm{kg}^{-1}\right)$ & 4.68 \\
$\mathrm{Mn}\left(\mathrm{mg} \mathrm{kg}^{-1}\right)$ & 12.64 \\
$\mathrm{Zn}\left(\mathrm{mg} \mathrm{kg}^{-1}\right)$ & 9.14 \\
$\mathrm{Cu}\left(\mathrm{mg} \mathrm{kg}^{-1}\right)$ & 7.32 \\
\hline
\end{tabular}

Çizelge 4. Varyans analiz sonuçları

\begin{tabular}{|c|c|c|c|c|c|}
\hline Varyasyon kaynağı & $\mathrm{df}$ & F Değeri & Varyasyon kaynağı & $\mathrm{df}$ & F Değeri \\
\hline \multicolumn{2}{|c|}{ Mavi Dalga Boyu $(450-500 \mathrm{~nm})$} & & \multicolumn{3}{|c|}{ Kırmızı Dalga Boyu (610-700 nm) } \\
\hline Organik gübre dozu (A) & 6 & $26.16 * *$ & Organik gübre dozu (A) & 6 & $32.51 * *$ \\
\hline Dönem (B) & 7 & $400.65 * *$ & Dönem (B) & 7 & $424.08 * *$ \\
\hline$A \times B$ & 42 & $13.77 * *$ & $\mathrm{~A} \times \mathrm{B}$ & 42 & $13.61 * *$ \\
\hline Hata & 112 & & Hata & 112 & \\
\hline \multicolumn{3}{|c|}{ Yeşil Dalga Boyu $(501-570 \mathrm{~nm})$} & \multicolumn{3}{|c|}{ Yakın Infrared (NIR) Dalga Boyu (701-1075) } \\
\hline Organik gübre dozu (A) & 6 & $17.31 * *$ & Organik gübre dozu (A) & 6 & 5.12 \\
\hline Dönem (B) & 7 & $291.39 * *$ & Dönem (B) & 7 & $139.90 * *$ \\
\hline $\mathrm{A} \times \mathrm{B}$ & 42 & $10.49 * *$ & $\mathrm{~A} \times \mathrm{B}$ & 42 & $4.89 * *$ \\
\hline Hata & 112 & & Hata & 112 & \\
\hline
\end{tabular}

**\% 1 düzeyinde önemli

Roka yetiştiriciliğinde üretim sezonu boyunca mavi, yeşil, kırmızı ve NIR bandlarda kaydedilen spektral yansımalar değerlendirildiğinde; mavi dalga boyunda elde edilen spektral yansımaların kontrol grubu ve katı+sıvı organik gübre uygulamaların tamamının üretim sezonunun sonuna doğru azalma eğiliminde oldukları belirlenmiştir (Çizelge 5, Şekil 2). Katı+sıvı organik gübre uygulamalarının spektral yansıma üzerine en fazla etkisi 4. ölçüm en az etkisi ise 8. ölçümde meydana gelmiştir (Çizelge 5). Katı ve sıvı organik gübre uygulamalarının roka bitkisinin spektral yansıması üzerindeki etkisi 1., 2., 3. ve 4. ölçümlerde daha belirgin iken diğer ölçümlerde ise bu etkinin daha sınırlı olduğu tespit edilmiştir (Çizelge 5). Aynı zamanda katı gübre ile birlikte uygulanan sıvı gübrelerin ise katı gübrelere göre mavi dalga boyundaki enerji kullanımında daha etkili olduğu belirlenmiştir. Diğer uygulamalardan farklı olarak $U_{2}$ uygulaması sonucunda roka bitkisinin mavi band aralığındaki spektral yansıması üzerindeki etkisi 4. ölçüme kadar genel olarak artış eğiliminde, sonraki ölçümlerde ise diğer uygulamalarda olduğu gibi azalış eğiliminde olduğu tespit edilmiştir. Uygulamaların mavi bant aralığındaki enerji kullanımındaki en belirgin farklılıklar ise 1., 2., 3., 4. ve 5. ölçümlerde gözlemlenmiştir (Şekil 2). Özellikle katı gübrelerin yoğun olduğu $U_{2}, U_{3}, U_{5}$ ve $U_{6}$ uygulamaları neredeyse ölçümlerin tamamında kontrol grubuna göre daha fazla spektral yansımanın ortaya çıktığı tespit edilmiştir (Çizelge 5). Sıv1 organik gübrelerin katı organik gübrelere göre mavi band aralığındaki spektral yansımalar üzerinde ise daha az artışa neden olduğu belirlenmiştir. 
Çizelge 5. Uygulamaların mavi band aralığındaki spektral yansıma üzerine etkileri

\begin{tabular}{|c|c|c|c|c|c|c|c|c|}
\hline & \multicolumn{8}{|c|}{ Mavi Band } \\
\hline & 1.Ölçüm & 2.Ölçüm & 3.Ölçüm & 4.Ölçüm & 5.Ölçüm & 6.Ölçüm & 7.Ölçüm & 8.Ölçüm \\
\hline $\mathrm{K}$ & $0.058 c A$ & $0.058 b A B$ & $0.056 a b C$ & $0.056 c d B C$ & $0.052 c D E$ & $0.052 a E$ & $0.054 b C D$ & $0.047 a F$ \\
\hline $\mathrm{U}_{1}$ & $0.062 b A$ & $0.057 b B$ & $0.055 a b C$ & $0.054 d C$ & $0.052 c D$ & $0.050 b E$ & $0.052 d D E$ & $0.045 b F$ \\
\hline $\mathrm{U}_{2}$ & $0.056 d C$ & $0.061 a B$ & $0.052 c D$ & $0.064 a A$ & $0.053 b c D$ & $0.047 e E$ & $0.053 c D$ & $0.047 a E$ \\
\hline $\mathrm{U}_{3}$ & $0.064 a A$ & $0.063 a A$ & $0.055 b B$ & $0.061 b A$ & $0.054 b c B$ & $0.049 b c C$ & $0.056 a B$ & $0.048 a C$ \\
\hline $\mathrm{U}_{4}$ & $0.061 b A$ & $0.053 c C$ & $0.052 c C$ & $0.057 c B$ & $0.053 b c C$ & $0.048 \mathrm{deD}$ & $0.052 c C$ & $0.045 b E$ \\
\hline $\mathrm{U}_{5}$ & $0.063 a b A$ & $0.061 a B$ & $0.057 a C$ & $0.055 c d D$ & $0.057 a C$ & $0.048 c d F$ & $0.051 d E$ & $0.048 a F$ \\
\hline $\mathrm{U}_{6}$ & $0.058 c B$ & $0.063 a A$ & $0.055 b C$ & $0.055 c d C$ & $0.055 a b C$ & $0.049 b c D$ & $0.055 b C$ & $0.045 b E$ \\
\hline $\operatorname{Max}$ & $0.064 a A$ & $0.063 a A$ & $0.057 a C$ & $0.064 a \mathrm{~A}$ & $0.057 a C$ & $0.052 a E$ & $0.056 a B$ & $0.048 a F$ \\
\hline Min & $0.056 d C$ & $0.053 c C$ & $0.052 c C$ & $0.054 d C$ & $0.052 c D$ & $0.047 e E$ & $0.051 \mathrm{dE}$ & $0.045 b E$ \\
\hline$C V$ & 4.90 & 6.15 & 3.55 & 6.65 & 3.57 & 3.20 & 3.17 & 3.07 \\
\hline
\end{tabular}

Büyük Harflendirmeler; Ölçümler (dönem) arasında, Küçük Harflendirmeler ise uygulamalar (katı+sıvı organik gübre ) arasındaki farklılığı göstermektedir

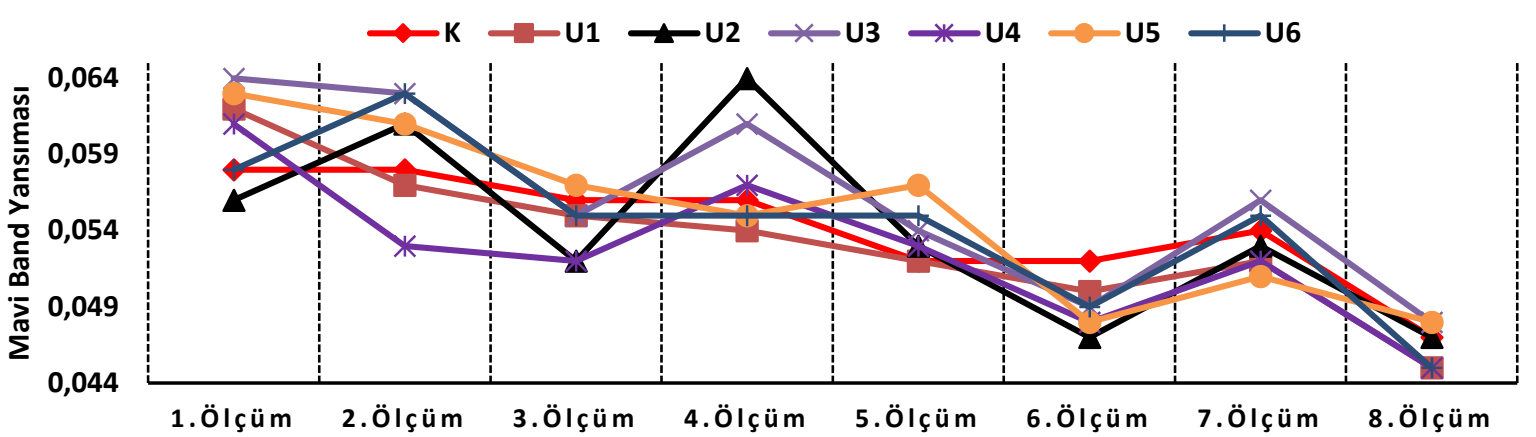

Şekil 2. Uygulamaların mavi dalga aralığındaki spektral yansıma üzerine etkilerinin üretim periyodu boyunca değişimi

Üretim sezonunun sonuna doğru kontrol grubu ve kat1+sıv1 organik gübre uygulamalarının tamamında yeşil band aralığında elde edilen spektral yansımaların azalma eğiliminde oldukları belirlenmiştir (Çizelge 6, Şekil 3). Katı ve sıvı organik gübre uygulamalarının roka bitkisinin spektral yansıması üzerindeki etkisi en fazla 5. ölçümde en az 3. ölçümde belirlenmiştir (Çizelge 6). Genel olarak organik gübre uygulamaları spektral yansıma üzerinde yetiştirme periyodunun olgunluk dönemlerinde (4., 5. ve 6. ölçüm dönemleri ) daha fazla varyasyona neden olmuştur. Spektral yansımanın artışı üzerinde katı gübrelerin 1., 2., 3. ve 4. ölçümlerde sıvı gübrelerin ise 5., 6., 7. ve 8. ölçümlerde daha etkili oldukları tespit edilmiştir. Altunbas ve ark., (2018b), Craig ve Shih (1998) yaptıkları bir çalışmada da, artan oranda uygulanan organik gübre dozlarının etkisinin elektromanyetik spektrumun 500-600 nm'deki yeşil-sarı spektral bölgede yansımada önemli bir artışla kendini gösterdiği belirlemişlerdir.

Çizelge 6. Uygulamaların yeşil band aralığındaki spektral yansıma üzerine etkileri

\begin{tabular}{|c|c|c|c|c|c|c|c|c|}
\hline & \multicolumn{8}{|c|}{ Yeşil Band } \\
\hline & 1.Ölçüm & 2.Ölçüm & 3.Ölçüm & 4.Ölçüm & 5.Ölçüm & 6.Ölçüm & 7.Ölçüm & 8.Ölçüm \\
\hline $\mathrm{K}$ & $0.178 c A$ & $0.171 c B$ & $0.148 b D E$ & $0.142 d F$ & $0.143 c F$ & $0.151 a C$ & $0.147 b c E$ & $0.150 a C D$ \\
\hline $\mathrm{U}_{1}$ & $0.186 a \mathrm{~A}$ & $0.176 b c B$ & $0.158 a D E$ & $0.164 a C D$ & $0.165 a C$ & $0.151 a E F$ & $0.147 b c F$ & $0.134 c d G$ \\
\hline $\mathrm{U}_{2}$ & $0.175 d A$ & $0.176 b c A$ & $0.157 a B$ & $0.156 c B$ & $0.172 a A$ & $0.128 d C$ & $0.152 a b B$ & $0.135 b c d C$ \\
\hline $\mathrm{U}_{3}$ & $0.184 b B$ & $0.194 a A$ & $0.154 a b D$ & $0.162 a b C$ & $0.152 b D$ & $0.145 b E$ & $0.145 c E$ & $0.142 b E$ \\
\hline $\mathrm{U}_{4}$ & $0.176 c d A$ & $0.173 c A$ & $0.158 a B$ & $0.157 b c B$ & $0.144 c C$ & $0.133 c D$ & $0.136 d C D$ & $0.132 d D$ \\
\hline $\mathrm{U}_{5}$ & $0.165 e D$ & $0.185 a b A$ & $0.158 a C$ & $0.166 a B$ & $0.153 b D$ & $0.148 a b D E$ & $0.148 b c E$ & $0.141 b c F$ \\
\hline $\mathrm{U}_{6}$ & $0.177 c d A$ & $0.178 b c A$ & $0.160 a B$ & $0.152 c D$ & $0.154 b C D$ & $0.145 b E$ & $0.157 a B C$ & $0.141 b c E$ \\
\hline $\operatorname{Max}$ & $0.186 a A$ & $0.194 a A$ & $0.160 a B$ & $0.166 a B$ & $0.172 a A$ & $0.151 a E F$ & $0.157 a B C$ & $0.150 a C D$ \\
\hline Min & $0.165 e D$ & $0.171 c B$ & $0.148 b D E$ & $0.142 d F$ & $0.143 c F$ & $0.128 d C$ & $0.145 c E$ & $0.132 d D$ \\
\hline$C V$ & 3.64 & 5.38 & 3.26 & 5.20 & 6.75 & 6.20 & 4.55 & 4.96 \\
\hline
\end{tabular}

Büyük Harflendirmeler; Ölçümler (dönem) arasında, Küçük Harflendirmeler ise uygulamalar (katı+sıvı organik gübre) arasındaki farklılı̆ı̆ göstermektedir 


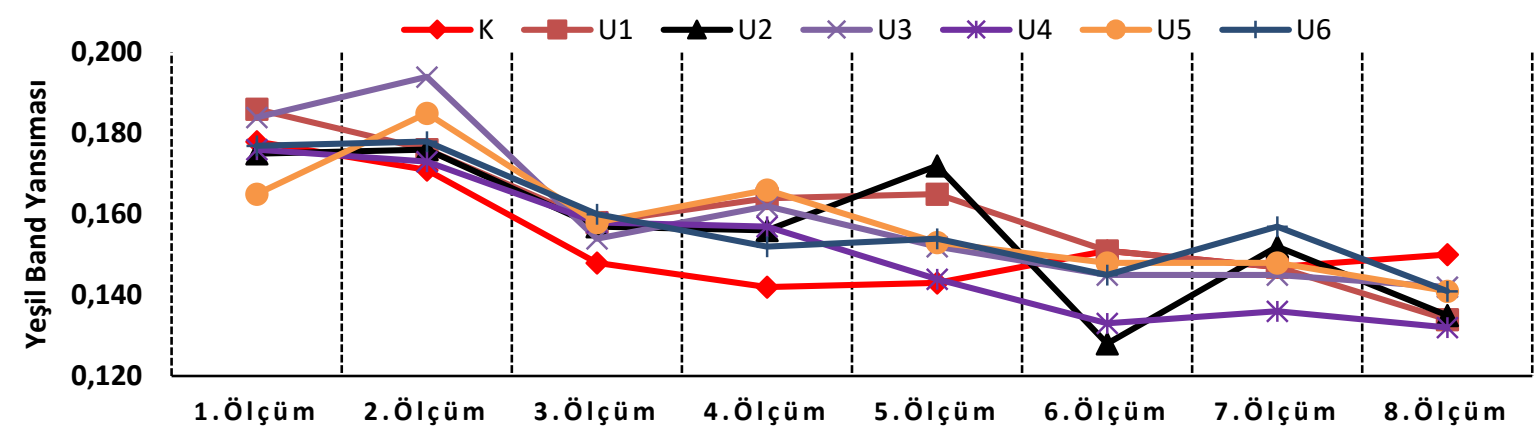

Şekil 3. Uygulamaların mavi dalga aralığındaki spektral yansıma üzerine etkilerinin üretim periyodu boyunca değişimi

Üretim sezonunun sonuna doğru kontrol grubu ve katı+sıv1 organik gübre uygulamalarının tamamında kırmızı band aralığında elde edilen spektral yansımaların azalma eğiliminde oldukları belirlenmiştir (Çizelge 6, Şekil 3). Sari ve ark., (2005b)' e göre elektromanyetik spektrumun kırmızı dalga boyunda düşük yansıma (yüksek enerji kullanımı) göstermesi fotosentez için yapraklardaki klorofil pigmenti tarafından enerjinin tutulması anlamına gelmektedir. Araştırmacıların bu bulguları ise üretim periyodunun sonuna doğru metabolik faliyetler sonucunda oluşan klorofil pigmenti miktarındaki artışın spektral yansımanın düşmesi üzerinde etkili olmuş olabileceği düşüncemizi desteklemektedir. Katı ve sıvı organik gübre uygulamalarının roka bitkisinin spektral yansıması üzerindeki etkisi en fazla 2. ölçümde en az 8. ölçümde belirlenmiştir (Çizelge 7). Katı ve sıvı gübre dozlarının özellikle ilk beş ölçümde spektral yansımanın artışı üzerinde etkili iken 6., 7 . ve 8. ölçümlerde ise genellikle kontrol grubundan dahi daha düşük spektral yansıma vermesinde etkili oldukları tespit edilmiştir (Çizelge 7).

Çizelge 7. Uygulamaların kırmızı band aralığındaki spektral yansıma üzerine etkileri

\begin{tabular}{|c|c|c|c|c|c|c|c|c|}
\hline & \multicolumn{8}{|c|}{ Kırmızı Band } \\
\hline & 1.Ölçüm & 2.Ölçüm & 3.Ölçüm & 4.Ölçüm & 5.Ölçüm & 6.Ölçüm & 7.Ölçüm & 8.Ölçüm \\
\hline $\mathrm{K}$ & $0.087 c d A$ & $0.088 d A$ & $0.077 b B$ & $0.074 e C$ & $0.074 b c C$ & $0.075 a C$ & $0.074 b C$ & $0.074 a C$ \\
\hline $\mathrm{U}_{1}$ & $0.097 a A$ & $0.090 c d B$ & $0.079 a b C$ & $0.076 e C D$ & $0.073 b c D E$ & $0.074 a b C D$ & $0.073 b D E$ & $0.068 c E$ \\
\hline $\mathrm{U}_{2}$ & $0.088 c A$ & $0.092 c d A$ & $0.080 a b B$ & $0.082 b c B$ & $0.083 a B$ & $0.065 e E$ & $0.070 c D$ & $0.075 a C$ \\
\hline $\mathrm{U}_{3}$ & $0.092 b B$ & $0.100 a A$ & $0.080 a b D$ & $0.084 a C$ & $0.074 b c E F$ & $0.074 a b E$ & $0.073 b F G$ & $0.072 b G$ \\
\hline $\mathrm{U}_{4}$ & $0.089 c A$ & $0.082 e B$ & $0.072 c D$ & $0.078 d C$ & $0.071 c D E$ & $0.067 d F$ & $0.069 c E F$ & $0.071 b D E$ \\
\hline $\mathrm{U}_{5}$ & $0.083 e B$ & $0.096 a b A$ & $0.082 a B$ & $0.083 a b B$ & $0.076 b C$ & $0.074 b c D$ & $0.073 b D$ & $0.071 b D$ \\
\hline $\mathrm{U}_{6}$ & $0.086 \mathrm{~dB}$ & $0.094 b c A$ & $0.083 a C$ & $0.080 c D$ & $0.076 b E$ & $0.072 c F$ & $0.077 a E$ & $0.070 b G$ \\
\hline $\operatorname{Max}$ & $0.097 a A$ & $0.100 a A$ & $0.083 a C$ & $0.084 a C$ & $0.083 a B$ & $0.075 a C$ & $0.077 a E$ & $0.075 a C$ \\
\hline Min & $0.083 e B$ & $0.082 e B$ & $0.072 c D$ & $0.074 e C$ & $0.071 c D E$ & $0.065 e E$ & $0.069 c E F$ & $0.068 c E$ \\
\hline$C V$ & 4.91 & 6.34 & 5.49 & 4.73 & 5.15 & 5.53 & 3.91 & 3.53 \\
\hline
\end{tabular}

Büyük Harflendirmeler; Ölçümler (dönem) arasında, Küçük Harflendirmeler ise uygulamalar (katı+sıvı organik gübre) arasındaki farklılığı göstermektedir

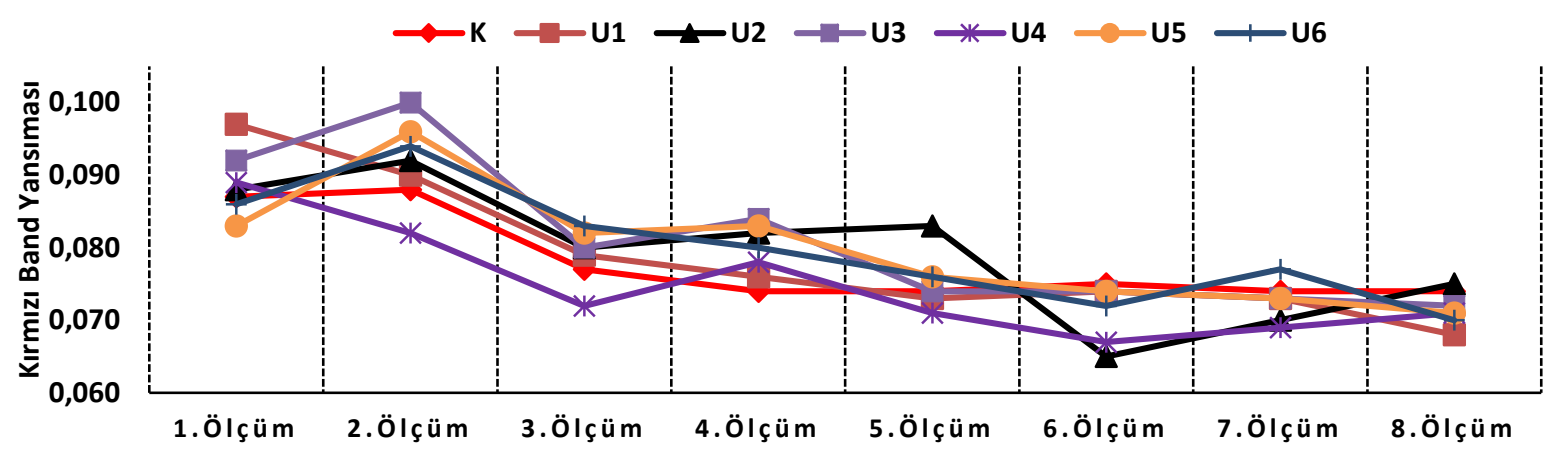

Şekil 4. Uygulamaların mavi dalga aralığındaki spektral yansıma üzerine etkilerinin üretim periyodu boyunca değişimi 
Bitkilerin stres koşullarının belirlenmesinde en önemli belirleyici dalga boyu aralığının elektromanyetik spektrumun yakın kızıl ötesi bölgesi olduğu pek çok araştırmacı tarafından ifade edilmektedir (Slaton ve ark.,2001; Lennartsson, 2003; Leone ve ark., 2007; Lillhonga ve Gelady, 2011; Cao ve Zhan, 2014; Zhao ve ark., 2017 ). Üretim sezonunun sonuna doğru kontrol grubu ve uygulamaların tamamında yakın kızıl ötesi band aralığında elde edilen spektral yansımaların 5. ölçüm hariç diğer ölçümlerde azalma eğiliminde oldukları belirlenmiştir (Çizelge 8, Şekil 5). Katı ve sıvı organik gübre uygulamalarının roka bitkisinin spektral yansıması üzerindeki etkisi en fazla 2. ölçümde en az 7. ölçümde belirlenmiştir (Çizelge 8). Kat1 ve sıv1 gübre dozlarının özellikle 6 . ve 8 . ölçümlerde spektral yansımada kontrol grubuna göre azalma, diğer ölçümlerde ise uygulamaların neredeyse tamamı spektral yansıma üzerinde artışa neden olmuştur (Çizelge 8). Çalışmadan elde edilen bulgular değerlendirildiğinde, artan dozlarda uygulanan organik gübrelerin sadece 2., 3., 4. ve 5. ölçüm dönemlerinde kontrol grubuna göre daha fazla spektral yansımada artışa neden olduğu tespit edilmiştir. Diğer ölçümlerde ise uygulamalar ile kontrol grubu arasında istatistiksel olarak fark olmasına karşılık spektral yansımada çok ciddi farklılıklar tespit edilmemiştir.

Çizelge 8. Uygulamaların NIR band aralığındaki spektral yansıma üzerine etkileri

\begin{tabular}{cllllllll}
\hline & & & \multicolumn{2}{c}{ NIR Band } \\
& 1. Ölçüm & 2. Ölçüm & 3. Ölçüm & 4. Ölçüm & 5. Ölçüm & 6.Ölçüm & 7.Ölçüm & 8. Ölçüm \\
\hline $\mathrm{K}$ & $0.991 a A$ & $0.915 b B$ & $0.892 c C$ & $0.879 e C$ & $0.911 d B$ & $0.863 b D$ & $0.910 c d B$ & $0.918 a B$ \\
$\mathrm{U}_{1}$ & $0.996 a A$ & $0.929 b C$ & $0.906 b c D$ & $0.918 a C D$ & $0.973 a B$ & $0.881 a E$ & $0.919 a C$ & $0.924 a C$ \\
$\mathrm{U}_{2}$ & $0.993 a A$ & $0.939 b B$ & $0.932 a B C$ & $0.901 c D$ & $0.973 a A$ & $0.831 d E$ & $0.917 a b$ & $0.907 b D$ \\
$\mathrm{U}_{3}$ & $0.946 b B C$ & $1.014 a A$ & $0.921 a b C D$ & $0.911 a b D E$ & $0.965 b B$ & $0.836 c d F$ & $0.914 a b c C D E$ & $0.884 c E$ \\
$\mathrm{U}_{4}$ & $0.984 a A$ & $0.924 b B$ & $0.902 b c B$ & $0.919 a B$ & $0.929 c B$ & $0.848 c C$ & $0.907 d B$ & $0.918 a B$ \\
$\mathrm{U}_{5}$ & $0.976 a A$ & $0.973 a b A$ & $0.908 b c B$ & $0.908 b c B$ & $0.965 b A$ & $0.845 c C$ & $0.912 b c d B$ & $0.918 a B$ \\
$\mathrm{U}_{6}$ & $0.980 a A$ & $0.976 a b A$ & $0.910 a b c B C$ & $0.889 d C$ & $0.975 a A$ & $0.862 b D$ & $0.912 c d B$ & $0.917 a B$ \\
$M a x$ & $0.996 a A$ & $1.014 a A$ & $0.932 a B C$ & $0.919 a B$ & $0.975 a A$ & $0.863 b D$ & $0.919 a C$ & $0.924 a C$ \\
$M i n$ & $0.946 b B C$ & $0.915 b B$ & $0.892 c C$ & $0.879 e C$ & $0.911 d B$ & $0.831 d E$ & $0.907 d B$ & $0.884 c E$ \\
$C V$ & 2.10 & 4.83 & 1.75 & 1.63 & 2.55 & 2.09 & 0.52 & 1.50 \\
\hline $\mathrm{B}$
\end{tabular}

Büyük Harflendirmeler; Ölçümler (dönem) arasında, Küçük Harflendirmeler ise uygulamalar (katı+sıvı organik gübre) arasındaki farklılığı göstermektedir

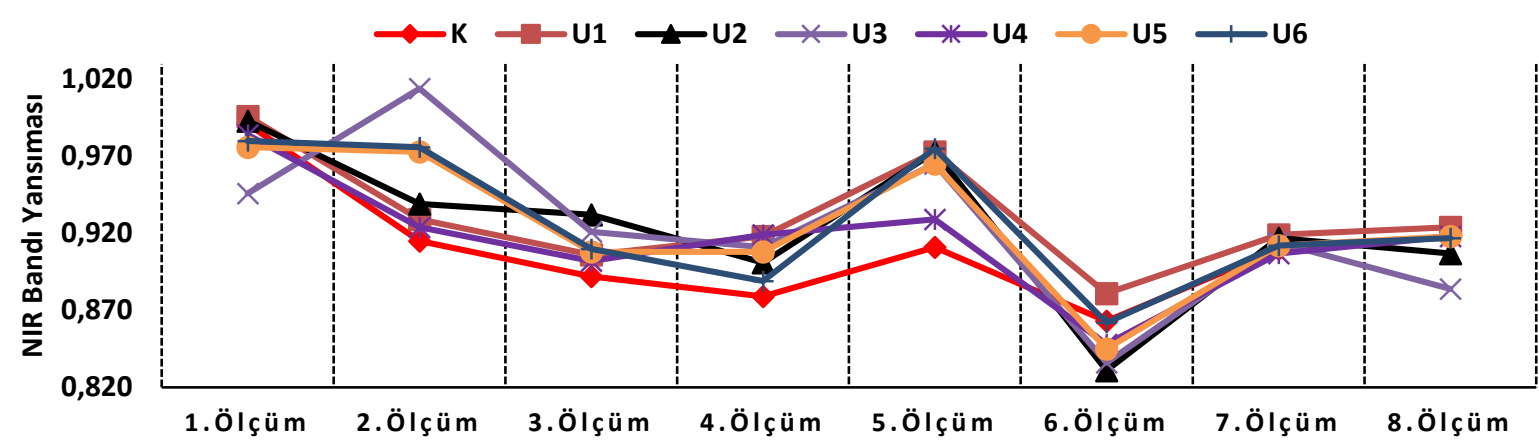

Şekil 5. Uygulamaların mavi dalga aralığındaki spektral yansıma üzerine etkilerinin üretim periyodu boyunca değişimi

\section{Sonuç}

Araştırma sonuçlarına göre, roka yetiştiriciliğinde spektral yansıma üzerine organik gübre dozu, dönem ve doz*dönem interaksiyonun etkileri istatistiksel olarak $\mathrm{P} \leq 0.01$ düzeyinde önemli bulunmuştur. Katı + sıvı organik gübre uygulamalarının spektral yansıma üzerinde oluşturduğu varyasyonun en fazla ve en az olduğu ölçümler sırasıyla mavi band bölgesinde; 4. ve 8. ölçümler, yeşil band bölgesinde; 5. ve 3. ölçümler, kırmızı band bölgesinde; 2. ve 8. ölçümler, yakın infrared band bölgesinde ise; 2. ve 7. ölçüm dönemlerinde tespit edilmiştir. $\mathrm{Bu}$ sonuçlar doğrultusunda varyasyonun en fazla ve en az olduğu ölçüm dönemlerinin bitki stres koşullarının tespit edilmesinde belirleyici olabileceği sonucuna ulaşılmıştır. Bitkilerin stres koşullarının belirlenmesinde en önemli 
belirleyici dalga boyu aralığının elektromanyetik spektrumun yakın kızıl ötesi bölgesi olduğu pek çok araştırmacı tarafından ifade edilmektedir. Bu kapsamda, araştırmada özellikle NIR bandındaki spektral yansıma sonuçlarına değerlendirildiğinde serada roka yetiştiriciliğinde genellikle uygulanan katı+sıvı organik gübre dozlarının roka bitki üzerinde 2. ve 5. ölçüm dönemleri hariç önemli düzeyde stres oluşturacak kadar etkili olamadığı belirlenmiştir. Bu teknik ve teknolojik yaklaşım, farklı dozlarda uygulanan sıv1+katı organik gübreden kaynaklı stres koşullarının, bitki henüz strese girmeden veya hangi yetişme periyodunda stresin daha etkili olduğunu ortaya çıkarabilmesi sonucunda olası verim ve kalite kayıplarını engelleyerek zamandan ve maliyetten tasarruf sağlayabilmektedir. Bu sonuçlar doğrultusunda, roka bitkisine farklı dozlarda uygulanacak olan organik gübrelerin spektral yansımasındaki artışlar/azalışlar üzerinde bitkinin hangi fiziksel ve kimyasal özelliği veya özelliklerinin etkili olduğu araştırılmalıdır.

\section{Kaynaklar}

Alagöz, Z., Yılmaz, E., \& Öktüren, F. (2006). Organik materyal ilavesinin bazı fiziksel ve kimyasal toprak özellikleri üzerine etkileri. A.Ü. Ziraat Fakültesi Dergisi. 19 (2), 245-254.

Altunbas, S., Gozukara, G., Sonmez, N.K., Maltaş, A.Ş., \& Kaplan, M. (2018a). Relationship between spectral reflectance and plant nutrient-chlorophyll content in lettuce (Lactuca Sativa L.) growing. Fresenius Environmental Bulletin 27(5A), 3624-3632.

Altunbas, S., Sonmez, N.K., Gozukara, G., Maltaş, A.Ş., \& Kaplan, M. (2018b). Relationship between solid-liquid organic fertilization and spectral reflectance in lettuce (Lactuca Sativa L.) growing. Fresenius Environmental Bulletin, 27(8), 5355-5362.

Başayiğit, L., Dedeoğlu, M., \& Akgül, H. (2015). The prediction of iron content in orchards using VNIR spectroscopy. Turkish Journal of Agriculture and Forestry. 39, 123-134.

Blackmer, T.M., Schepers, J.S., \& Varvel, G.E. (1994). Light reflectance compared with other nitrogen stress measurements in corn leaves. Agronomy Journal, 86, 934-938.

Black, C.A. (1965). Methods of Soil Analysis. Part 2, Amer. Society of Agronomy Inc., Publisher Madisson, Wilconsin, U.S.A., 1372-1376.

Bouyoucos, G.J. (1955). A recalibration of the hydrometer method for making mechanical analysis of the soils. Agronomy Journal. 4(9), 434.

Cao H., Zhan Y. (2014). Near-infrared spectra quantitative analysis for flue gas of thermal power plant based on wavelength selection. Scientific Research and Essay 9, 288-292.

Chappelle, E.W., Kım, M.S., \& Mcmurtrey, J.E. (1992). Ratio analysis of reflectance spectra (RARS): an algorithm for the remote estimation of the concentrations of chlorophyll a, chlorophyll b, and carotenoids in soybean leaves. Remote Sensing of Environment, 39, 239-247.

Gözükara, G., Kalkan, H., \& Kaplan, M. (2014). Evaluation of differences in fertilizer consumption of autumn tomato production in greenhouse. 9 th International soil science congress. 14-16 October. Antalya. 685-689.

Gözükara, G., Kaplan., M. \& Kalkan, H. (2016). Evaluation of Soil Analysis Results and Fertilizer Consumption in Autumn Greenhouse Tomato Cultivation. 2. International Conference on Science, Ecology and Technology. 14-16 October. Barcelona. 721-726.

Gözükara, G., Altunbaş, S., Şimşek, O., Sarı, O., Buyurgan, K., Maltaş, A.Ş., Sönmez, N.K. \& Kaplan, M. (2019). Roka (Eruca vesicaria) yetiştiriciliğinde spektral yansıma ile bitki besin maddesi konsantrasyonu arasındaki ilişkinin belirlenmesi. Mediterranean Agriculturel Sciences. 32, 55-62.

Horuz, A., 2002. Bafra ve Çarşamba Ovalarında toprakların azot durumlarını belirlemekte kullanılan bazı kimyasal yöntemlerin misır bitkisi yetiştirerek tarla denemeleriyle kalibrasyonları. ilişkileri. Ondokuz Mayıs Üniversitesi, Fen Bilimleri Enstitüsü, Doktora Tezi, 121 s., Samsun

Evliya, H. (1964). Kültür Bitkilerinin Beslenmesi. Ankara. Üniv. Ziraat Fak. Yayınları, Yayın no:36, 292- 294 Ankara.

Jackson, R.D. (1984). Remote sensing of vegetation characteristics for farm management. Sixth in the SPIE Critical Reviews of Technology Series: Remote Sensing 475, 81-96.

Jackson, M.C. (1967). Soil Chemical Analysis. Prentice Hall of India Private'Limited, New Delhi.

Kacar, B. (1995). Bitki ve Toprağın Kimyasal Analizler: III. Toprak Analizleri. A. Ü. Ziraat Fakültesi Geliştirme Vakfı Yayınları No: 3. 
Kacar, B. \& İnal, A. (2008). Bitki Analizleri. Nobel Yayın Dağıtım, Ankara.

Kalkan, H., Gözükara, G., \& Kaplan, M. (2017). Sera Güzlük Domates Yetiştiriciliğinde Yeni Eğilim: Sıvı Organik Gübre Tüketimi. Academia Journal of Engineering and Applied Sciences. 2(3), 92-100.

Kellog, C.E. (1952). Our Garden Soils. The Macmillan Company, Newyork.

Lennartsson, M., \& Ögren, E. (2003). Predicting the cold hardiness of willow stems using visible and near-infrared spectra and sugar concentrations. Trees-Structure Function. 17, 463-470.

Leone, A.P., Menenti, M., Buondonno, A., Letizia, A., Maffei, C., \& Sorrentino, G. (2007). A field experiment on spectrometry of crop response to soil salinity. Agricultural Water Management $89,39-48$.

Lillhonga, T., Geladi, P. (2011). Three-way analysis of a designed compost experiment using nearinfrared spectroscopy and laboratory measurements. J Chemometrics 25, 193-200.

Lindsay, W.L., \& Norvell, W.A. (1978). Development of a DTPA soil test for Zinc, Iron, Manganese and Copper. Soil Sci. Amer. Jour., 42 (3), 421-428. Madisson, Wilconsin, USA, p. 1372-1376.

Loue, A. (1968). Diagnostic petiolaire de prospection etudes sur la nutrition et al. fertilisation potassiques de la vigne. Societe Commerciale des Potasses d'Alsace Services Agronomiques, 31-41.

Merzlyak, M.N., Gitelson, A.A., Chivkunova, O.B., Solovchenko, A.E., \& Pogosyan, S.I. (2003). Application of reflectance spectroscopy for analysis of higer plant pigments. Russian Journal of Plant Physiology 50, 704-710.

Olsen, S.R. \& Sommers, E.L. (1982). Phosphorus Soluble in Sodium Bicarbonate, Methods of Soil Analysis, Part 2, Chemical and Microbiological Properties. Edit: A.L. Page, P.H. Miller, D.R. Keeney 404-430.

Pizer, N.H. (1967). Some advisory aspect soil potassium and magnesium. Tech. Bull No: 14-184.

Rahman, S., Vance, G.F., \& Munn, L.C. (1994). Detecting salinity and soil nutrient deficiencies using SPOT satellite data. Journal of Soil Science 158, 31-39.

Sari, M., Sonmez, N.K., \& Kurklu, A. (2005a). Determination of seasonal variation of solar energy utilization by the leaves of Washington Navel Orange Trees (Citrus sinensis L. Osbeck). International Journal of Remote Sensing 26, 3295-3307.

Sari, M., Sonmez, N.K., \& Karaca, M. (2005b). Relationship between chlorophyll content and canopy reflectance in washington navel orange trees (citrus sinensis (L.) osbeck). Pak. J. Bot., 37(4), 1093-1102.

Slaton, M.R., Hunt, E.R., \& Smith, W.K., (2001). Estimating near infrared leaf reflectance from leaf structural characteristics. American Journal of Botany 88(2), 278-284.

Sonmez, N.K., Emekli, Y., Sari, M., \& Bastug, R. (2008). Relationship between spectral reflectance and water stress conditions of Bermuda grass (Cynodon dactylon L.). New zealand journal of agriculturel Research. 51, 223-233.

Sonmez, N.K., \& Sari, M., Sonmez, S. (2008). Relationship between mineral content and canopy reflectance in Washington navel orange trees. Asian journal of chemistry. 20(6), 4760-4772.

Sonmez, N.K., Aslan, G.E., \& Kurunc, A. (2015). Relationship spectral reflectance under different salt stress conditions of tomato. Jorunal of agriculturel sciences. 21, 585-595.

Thun, R., Hermann, R., \& Knickman, E. (1955). Die untersuchung von boden neuman verlag, Radelbeul und Berlin, s: 48-48.

Uz, İ., Sönmez, S., Tavali, İ.E., Citak, S., Üras, D.S., \& Çitak, S. (2016). Effect of Vermicompost on Chemical and Biological Properties of an Alkaline Soil with High Lime Content during Celery (Apium graveolens L. var. dulce Mill.) Production", Notulae Botanicae Hort1 Agrobotanic1 Cluj-Napoca, vol.44, pp.280-290.

Viscarra, Rosse,1 R.A., Walvoort, D.J.J., McBratney, A.B., Janik, L.J., \& Skjemstad, J.O. (2006). Visible, near infrared, mid-infrared or combined diffuse reflectance spectroscopy for simultaneous assessment of various soil properties. Geoderma 131, 59-75.

Vural, H., Eşiyok, D., \& Duman, İ. (2000). Kültür Sebzeleri (Sebze Yetiştirme). Ege Üniversitesi Ziraat Fakültesi Bahçe Bitkileri Bölümü, Bornova, İzmir, S. 440.

Zhao, D., Reddy, K.R., Kakanı, V.G., Read, J.J., \& Carter, G.A. (2003). Corn (Zea mays L.) growth, leaf pigment concentration, photosynthesis and leaf hyperspectral reflectance properties as affected by nitrogen supply. Plant and Soil, 257:205-217. 
Zhao, C., Liu, L., Wang, J., Huang, W., Song, X., \& Li, C. (2005). Predicting grain protein content of winter wheat using remote sensing data based on nitrogen status and water stress. International Journal of Applied Earth Observation and Geoinformation 7: 1-9.

Zhao, D., Starks, P.J., Brown, M.A., Phillips, W.A., \& Coleman, S.W. (2007). Assessment of forage biomass and quality parameters of bermudagrass using proximal sensing of pasture canopy reflectance. Grassland Science, 53:39-49.

Zhao, X., Hui, B., Hu, L., Cheng, Q., Via, B.K., Nadel, R., Starkey, T., \& Enebak, S. (2017). Potential of near infrared spectroscopy to monitor variations insoluble sugars in Loblolly pine seedlings after cold acclimation. Agricultural and Forest Meteorology 232:536-542.

Yilmaz, E., \& Sönmez, M. (2017). The role of organic/bio-fertilizer amendment on aggregate stability and organic carbon content in different aggregate scales. Soil\&Tillage Research. 168:118-124.

White, K. (1998). Remote Sensing. Progress in Physical Geography 22(1): 95-102. 